\title{
Reconstruction of Humanism Accomplishment Education of Technological Innovative Talents in Chinese Universities' Double First Class
}

\author{
Xue-Ting $\mathrm{LI}^{\mathrm{a}}$, Qing-Qing $\mathrm{LI}^{\mathrm{b}}$, Jun YANG ${ }^{\mathrm{c}}$ \\ ${ }^{1}$ Center for Digitized Culture and Media of UESTC, ${ }^{2}$ School of Public Administration \\ Chengdu, Sichuan
}

Email:18335781254@163.com

\begin{abstract}
Keywords: Two-class construction policy of China, Technological innovative talents, Humanism accomplishment.
\end{abstract}

\begin{abstract}
The humanism accomplishment of technological innovative talents is the soul of the survival and development of first-class universities, but it has been neglected in China for quite a long time. Now, China's "double first class" strategy has injected new connotation and provided new opportunities for the development of Chinese universities. Universities should bring the humanism accomplishment education of scientific and technological innovative talents into the big pattern of "two first-class" construction, so that students can learn humanistic knowledge in experience and perception, form humanistic emotions, thus improve creativity, scientificity and foresight of innovation, and become a real first class Talent.
\end{abstract}

\section{Introduction}

Before the opening of "13th Five-Year Plan", China has released the overall plan of building a world class university and the first class disciplines, "two first-class" construction for short, which is another major measure in the field of higher education in China after the "211 Project" and "985 Project". The plan clearly regards the inheritance of innovative and excellent culture as one of the five tasks of reform, which shows that the university is shouldering the important mission of inheriting excellent culture and cultivating humanistic quality.

In the past 30 years of reform and open, the concept of quality education has become the common understanding of Chinese education. However, higher education has paid more attention to the instrumental value and technological value for a long time in the past, and has neglected the cultivation of the humanistic quality of college students, especially in science and engineering. Humanism accomplishment education is committed to cultivating scientific and technological innovative talents with healthy personality, emphasizing people oriented and moral ethics, which is in line with the requirements of "double first-class" construction for high high-quality innovative talents. Therefore, it becomes the indispensable part of the innovative talents cultivation process.

In view of this, This paper, based on the analysis of the various social problems caused by the lack of humanistic quality of scientific and technological innovative talents, analyzes the important role of humanistic quality to the training of first-class talents, and discusses how to reconstruct the humanistic quality system of scientific and technological innovative talents under the background of "two first-class" construction.

\section{The Concept of Humanistic Quality and Its Evolution}

Just as the spatial deflection of culture makes it easy to change with time, "humanity" is not a fixed concept. The concept of "humanity" in China which germinated in the May 4th movement, on the basis of inheriting the essence of traditional humanistic thought, absorbs the essence of western humanism, and has a rich and clear connotation.

Humanities is human knowledge, including literature, history, philosophy, aesthetics, etc. And it is the inherent quality of combination of ability elements and mental factors. With the refinement of the division of discipline, many scholars divide the humanities into medical humanities, history and 
humanities according to their own subject background, and some scholars have refined the humanities qualities according to their social roles. This means that there seems to be different standards and connotations in humanistic quality in different fields. But in fact, the core of humanities qualities in different professional fields is the same, that is, "people-oriented", but the characteristics of different times have given a richer connotation of humanistic quality. Humanistic quality is based on human nature, highlighting the connotation of humanistic spirit related to ideals, beliefs and cultural character. Compared with practical skills, humanistic accomplishment emphasizes the potential accomplishment of personality.

\section{Humanistic Quality is the Soul Nourishment of Technological Innovative Talents in the Construction of "Double First Class"}

The humanistic quality, based on the profound knowledge of literary history and philosophy, highlights the ideal, belief, cultural character and creative spirit of human beings, and emphasizes the idea of human centered.

\section{Humanistic Quality Promotes the Perfection of Innovative Personality}

Innovative personality is the mental foundation of innovation activities[1]. It is a kind of innovative spirit, which can keep the innovation will and creativity of innovative talents when facing increasingly fierce competition, and maintain a long competitive advantage. In the process of innovation, people will inevitably encounter setbacks and obstacles. If there is a lack of healthy creative personality, it is easy to fall into the shackles of copying and imitation, making innovation become water without a source. On the basis of a profound humanistic knowledge system, humanistic quality can provide a broad knowledge background for scientific and technological innovative talents, encourage them to maintain a strong curiosity about the world and form a lasting spirit of inquiry. It can also help them establish a harmonious relationship with the objective world and have good psychological quality.

\section{Humanistic Quality Inspires Creative Thinking}

The Innovative thinking is the key to innovation activities. Scientific knowledge emphasizes the importance of objective and logic, guides people to think rationally, while humanities knowledge can form a non logical and divergent mode of thinking in the process of continuous accumulation, which helps technological innovative talents break disciplinary boundaries and mindset, have skip thinking and imagination, or form an intuitive way of thinking. Intuitive thinking is to judge, guess, without the gradual analysis of the problem. and sometimes it can even help people to make creative foresight. To form this intuitive thinking, we must have a rich knowledge base, that is, we must have good humanism accomplishment.

\section{Humanistic Quality Provides Guidance for the Technological Application}

Technology is a double-edged sword. The rapid development of data technology has brought a great wealth of human material civilization, and also a series of social problems, such as data leakage and trust crisis. The use of technology requires restrictions and guidance. The moral and legal consciousness formed in the long history is like an "internal self-discipline", which can help people to clear the baseline of the law and avoid infringing the legitimate rights and interests of others. The humanistic spirit of people-oriented can help scientific and technological innovative talents correctly understand the relationship between individual behavior and social development. It emphasizes that technology should serve for the overall interests of mankind, which makes them consider more about the fate of mankind and the development of human society when applying science and technology. It can be said that the humanities quality inspires the direction of the development of science and technology. 


\section{Lack of Humanistic Quality Cultivation -- the Shackles of "Double First Class" Construction}

Nowadays, all kinds of talents are generally weak in legal consciousness, lack of sense of social responsibility and political enthusiasm, but have high technical level, strong self-consciousness and multiple values. This reflects the lack of humanistic quality, and it makes it easier for their original values and moral standards to collapse under the great impact of the wave of technology.

\section{Lack of Humanistic Connotation and Innovation Ability}

At present, China is in the period of social transformation. The lack of attention to the cultivation of humanistic literacy has become a general phenomenon. It can be seen from the increasing number of scientific knowledge and skills courses and the continuous reduction of humanities courses. This problem is particularly serious in the universities of science and technology. According to a survey, $75 \%$ of students believe that the proportion of lectures on humanities quality held by schools (colleges) is too low[2]. This fully reflects the fact that due to the neglect of humanities and quality education in universities and society, the main body of training is also beginning to neglect their own humanities accomplishment. This leads to the lack of humanistic atmosphere, and gradually the talents are generally lack of deep humanism details.

\section{Moral Anomie and Fierce Egoism}

In some universities, employment rate and going abroad rate are taken as targets. Some college students are affected by this, so it is easy for them to take personal interests as the only reference. Qian Liqun, a Chinese humanist, once pointed out that "some of our universities, including Peking University, are training some delicate egoists". As an extreme individualism, egoism is overemphasizing personal value in the increasingly fierce social competition, and lacks social responsibility and dedication. This is reflected in the value orientation of technological innovation talents as follows: the decisive force of moral concept is weakening, and the decisive power of material interest, on the contrary, is increasing rapidly. In other words, they will take material interest more important.

\section{Lack of Legal Knowledge and Frequent Information Crime}

In recent years, Big data technology has been pursued by all circles of society because of its excellent insight into the hidden links between data. But it is worth noting that disregard of data ownership and data transactions will bring legal risks to both the social information order and the transactors. The level of legal knowledge of scientific and technological innovative talents directly affects their personal behavior. Researchers found that when asked whether to pay attention to information privacy of others, only $30 \%$ of the students said "very attentional"[4]. This reflects the weakness of the contemporary college students' data ethics and the lack of legal knowledge, and also reflects the absence of relevant legal education in the process of training the talents in the present university.

\section{New Requirements and Training Ways of "Double First Class" Construction for Technological Innovative Talents' Humanistic Quality}

Long Yingtai, a former culture minister and a humanist in Taiwan, once said, "what we encounter today is like an era of 'everything is OK ‘. From the era of single value, we entered an era of multiple values. " But the value diversification does not mean that we do not need to stick to the value, it is that with the different characteristics of the times we need to have a deeper accumulation of humanistic quality to help us to better understand the world and carry out innovative practice. Therefore, we need to reconstruct the humanistic quality combined with the new stage, new situations and new problems.

In this paper, the requirements of the "double class" construction on the humanistic quality of scientific and technological innovation talents are summed up into four aspects: humanistic 
knowledge, humanistic spirit, legal consciousness and data ethics. The four basic aspects and the core content are illustrated in Figure 1.

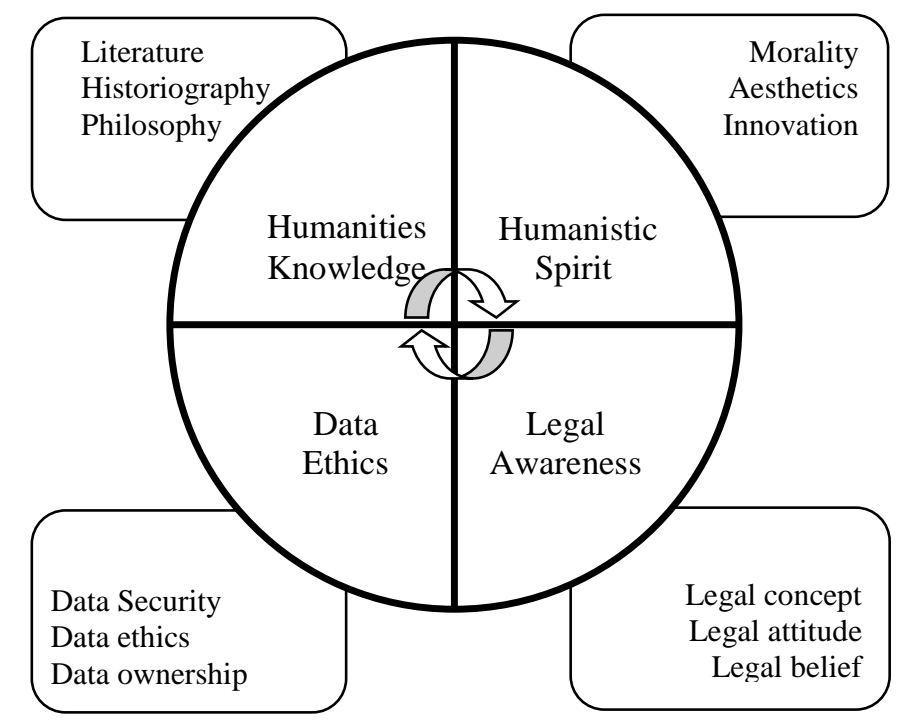

Fig. 1 The four basic aspects and the core content

\section{Set up the Modern Education Idea, Strengthen the Humanities Knowledge Education}

Humanistic knowledge is the basis of humanistic quality, and it is mainly based on literature, historiography and philosophy. Literature is based on authenticity and it is an aesthetic reflection of real life. Historiography has the function of reference for politics and enlightening the mind. It helps individuals to locate themselves and grasp the laws of human social development. Philosophy can guide people to think deeply about the relationship between human beings and nature and society in a unique way, and help form a scientific thinking mode. The accumulation of rich humanities knowledge can be internalized into deep cultural details, which is conducive to the formation of innovative thinking.

Modern education is concerned about the comprehensiveness and integrity of students' development, scientific knowledge, rational thinking and humanistic knowledge, so as to cultivate the sense of sensibility and beauty. Therefore, universities must pay attention to the comprehensiveness of discipline system, strengthen the education of humanities knowledge, and set up the curriculum system of humanistic quality education. Diversified curriculum selection and assessment mechanisms should also be developed to enable students to choose courses according to their professional needs and hobbies. At the same time, humanities courses should be appropriately improved credit requirements as an appropriate constraint, so that the humanities knowledge education can be guaranteed.

\section{Create a Humanistic Atmosphere, Develop Practical Training and Cultivate Humanistic Spirit}

The essence of humanistic quality is not about "skill" but "people-oriented" and "human centered" spirit. Its core is to care for the meaning and value of human existence. This is called the "humanistic spirit". It is the unity of scientific innovation spirit, aesthetic spirit and moral spirit formed by the integration of humanities knowledge. It pursues the glorious realm of life and society, advocates freedom of thought and emancipation of personality, and emphasizes that all innovative actions should be attributed to concern for human beings.

The simple process of learning knowledge cannot be transformed directly into individual thought and consciousness. Universities should also actively create a strong humanistic atmosphere for the cultivation of students' humanistic spirit. "Internet + learning" model, with independent selection and personalized learning platform, enables students to be their own master, and get rid of the psychological oppression caused by compulsory learning, feel free to choose their own interests. In 
addition, the innovation of student assessment and teacher evaluation mechanism is conducive to promoting interaction and communication between teachers and students, making the humanistic education process more humanistic. Furthermore, Practical exercise plays a catalytic role in the internalization of humanities knowledge. Schools should actively carry out all kinds of practical activities that are conducive to improving students' humanistic quality.

\section{Building a Cloud Platform for Big Data Management to Monitor Students'}

Legal consciousness is the guarantee of the humanistic quality of technological innovative talents in the new era. It includes legal concepts, legal attitudes and legal beliefs. Legal concepts urge technological innovative talents to defend their legitimate rights by law. The legal attitude requires that technological innovative talents observe their duty and respect others' legitimate rights while have their personal rights. Legal belief helps to enhance college students' sense of discipline. It can be said that it is a rule and a discipline, and the bottom line in the innovation practice.

Universities should make full use of their advantages in information collection and management, and establish "cloud platform" of big data management to carry out legal knowledge education. On cloud platform, we can offer quality courses for all subjects provide technical crime cases and discuss areas for legal issues. By setting up the characteristic database of different disciplines, digging out the students' selective learning data on the relevant legal courses and extracting the key words of the students speaking in the discussion area, analyzing the students' legal knowledge level, and monitoring their legal awareness. In this way, schools can carry out targeted legal knowledge education for students. It can also carry out personalized service functions such as legal resource customization, information push and other personalized services, so that students can improve their awareness of law in the process of learning legal knowledge.

\section{Conducting Education in Various Fields}

Data ethics is the criterion of humanistic quality of technological innovative talents in the new era. It includes data security, data morality and data ownership. In the era of big data, data become an important strategic resource in all trades and professions. Data ethics requires technological innovative talents to enhance data safety awareness, and to use data resources accurately and reasonably[5]. The clear ownership of data can avoid the private resale of data, otherwise it will cause social security panic and distrust of data technology. In the long run, that will affect the further development and utilization of big data.

There are different knowledge systems and research fields in different disciplines, which have different understanding and learning needs for data knowledge and criteria. Therefore, to carry out data ethics education for students in different disciplines, we should understand the data content, types, methods and means of data processing of different disciplines, and understand their respective data management needs and the data ethical problems that they may encounter. Such pre education analysis can lay a foundation for the targeted development of data ethics education.

\section{Conclusion}

After The comprehensive quality of technological innovative talents is the core competitiveness of a university and the key point to become a world-class university. With the deepening of China's higher education reform, the "double first" construction strategy is bound to break the barriers of key universities and local colleges and universities, and bring opportunities and challenges for universities with cultural competitiveness. These four aspects infiltrate into the life cycle of scientific and technological innovation, and affect the various stages of innovation activities. In order to improve the humanistic quality of scientific and technological innovative talents in the era of big data, it is necessary to learn humanistic knowledge in experience, form humanistic emotions, condense human will and practice humanistic behavior. Further to improve creativity, scientificity and foresight, let the humanities quality of technological innovation talents become the qualities and characters of the university. So as to upgrade a number of high-level universities and disciplines 
into world-class universities and disciplines. Finally, we will form a first-class higher education system and realize the dream of national prosperity by cultivating talents through higher education.

\section{References}

[1] Guo Chuanjie. On science and technology and spiritual civilization (2) [M]. Science Press, 2002. In Chinese

[2] Tu Gangpeng. The Investigation and analysis of the status of humanities quality of college students in science and Engineering [J]. Party building and ideological education in schools, 2014 (5): 72-74. In Chinese

[3] Liu Haohong, an analysis of multicultural trend of thought and College Students' Ideological and political education [J]. education and occupation , 2006 (17): 69-71. In Chinese

[4] Qu Deqiang, Li Chencai. The analysis and training methods of data literacy of contemporary college students [J]. ideological and political education research, 2015 (4): 99. In Chinese

[5] Hao Yuanling, Shen Tingting. Data literacy and its cultivation of thinking and strategy of constructing mechanism. Information theory and practice [J]. 2016 (1): 58-63. In Chinese 